\title{
The Management of Blood Loss in Non-Syndromic Craniosynostosis Patients Undergoing Barrel Stave Osteotomy
}

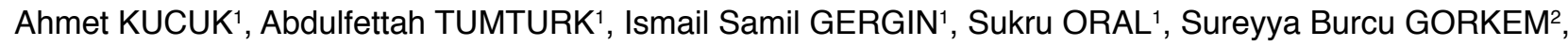 \\ Ali KURTSOY', Halit MADENOGLU³ , Ibrahim Suat OKTEM ${ }^{1}$ \\ ${ }^{1}$ Erciyes University, Faculty of Medicine, Department of Neurosurgery, Kayseri, Turkey \\ 2Erciyes University, Faculty of Medicine, Department of Radiology, Kayseri, Turkey \\ ${ }^{3}$ Erciyes University, Faculty of Medicine, Department of Anesthesiology and Reanimation, Kayseri, Turkey
}

\section{ABSTRACT}

AIM: Barrel stave osteotomy is a widely used procedure in neurosurgery for the majority of craniosynostosis patients. Both in the intraoperative and postoperative periods, there is inevitable leakage type bleeding from the bones undergoing osteotomy. A number of studies have been performed in order to prevent this complication but a concise procedure is still lacking.

MATERIAL and METHODS: Synostectomy and parietotemporal barrel stave osteotomy were applied to 143 patients who were operated on with a diagnosis of craniosynostosis between the years 2005-2013. At the beginning to osteotomy, $5 \mathrm{ml} / \mathrm{kg}$ erythrocyte suspension (ES) was given for probable blood loss. Whole blood count was performed at the postoperative $1^{\text {st }}$ and $6^{\text {th }}$ hours and cases with hemoglobin levels below 10 or with hematocrit levels which had decreased more than $5 \%$ between the $1^{\text {st }}$ and $6^{\text {th }}$ hours were administered erythrocyte transfusion.

RESULTS: Of the patients, 100 were boys and 43 were girls. Of these, 98 had metopic, 30 had sagittal, 9 had metopic+sagittal, 4 had unilateral, 2 had bilateral and 6 had coronal synostosis. All the cases were administered intraoperative erythrocyte suspension. The preoperative amount of administered mean erythrocyte was $8.61 \mathrm{ml} / \mathrm{kg}$. In the postoperative period, 92 patients were administered erythrocyte suspension. The postoperative amount of administered mean erythrocyte suspension was $7.98 \mathrm{ml} / \mathrm{kg}$.

CONCLUSION: For an operated infant with craniosynostosis who is operated on in the first year of life, undergoing osteotomy and inevitable bone-borne blood losses are very important and these have to be replaced immediately.

KEYWORDS: Craniosynostosis, Barrel stave osteotomy, Blood loss

\section{INTRODUCTION}

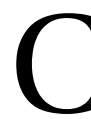
raniosynostosis is the early and pathologic closure of one or more sutures in the cranium, generally causing an abnormal appearance (21). Although craniosynostosis cases are referred to a physician for cosmetic reasons, the main aim of neurosurgeons in treating craniosynostosis is to relieve an increase in potential intracranial pressure on the neural tissues and prevent and or treat disorders of cognitive function. Thus, a widely used procedure in neurosurgery, barrel stave osteotomy, is applied to the majority of craniosynostosis cases. Hypothermia and hypovolemia are the most important causes of morbidity and mortality in surgical interventions of craniosynostosis (18). During surgery, heating blankets are used in an attempt to keep the body temperature stable and it may be monitored continuously by a probe. However, it is nearly impossible to objectively evaluate the amount of bleeding in the calvarium while undergoing a barrel stave osteotomy. Therefore, the intraoperative observations of the surgeon, his experience, and his communication with the anesthetist and monitoring of vital signs are important in determining perioperative blood and fluid losses (13).

Our aim was to evaluate blood loss and administration of blood products in patients being operated on to treat craniosynostosis, while taking age, body weight, type of craniosynostosis, preoperative and postoperative hemoglobin and hematocrit levels in to consideration. 


\section{MATERIAL and METHODS}

One hundred and forty three cases operated on by the same surgical team with the diagnosis of craniosynostosis in Erciyes University, Faculty of Medicine, Department of Neurosurgery between the years 2005-2013 were included. Preoperative whole blood count, biochemistry, prothrombin time, active partial thromboplastin time and international normalized ratio (INR) tests were performed. Patients with hemoglobin levels below 9 were administered a $10 \mathrm{ml} / \mathrm{kg}$ erythrocyte suspension (ES) preoperatively to increase hemoglobin levels as recommended by consulted pediatricians. Patients with an abnormal thrombocyte count and INR values were excluded. In order to evaluate the cranium, preoperative brain tomography and three-dimensional cranium tomography were conducted. The cases were consulted with the Department of Pediatrics both in the preoperative and postoperative periods.

\section{Surgical Technique}

In order to prevent hypothermia, a blanket was placed on the operating room table. Patients were placed in supine and horseshoe headed position. The operation site was cleaned with chlorhexidine solution for three minutes. In the preoperative period, prophylactic antibiotics (30 minutes before surgery $40 \mathrm{mg} / \mathrm{kg}$ cefazolin sodium) were administered. In order to relieve blood loss and postoperative pain, $10 \mathrm{mg} /$ $\mathrm{ml}$ of local anesthetics were applied with an injector washed with epinephrine to the dermal incision sites. A bicoronal dermal incision was performed. Dermal bleeding was controlled using a bipolar thermal cautery probe. The skin was elevated to keep periosteum on the bone. Afterwards, the periosteum was scraped from the bone and bone-borne bleedings were closed with bonewax. Frontal craniectomy, frontoorbital advancement, remodeling and biparietal barrel stave osteotomy were performed for cases with metopic synostosis; sagittal synostectomy and biparietal barrel stave osteotomy were performed for cases with sagittal synostosis; bifrontoorbital improvement, bifrontal craniotomy, bilateral barrel stave osteotomy and orbital apex osteotomy were performed for cases with unilateral coronal synostosis; bilateral coronal synostectomy, frontoorbital reshaping, bifrontal and biparietal barrel stave osteotomy were performed for cases with bilateral coronal synostosis. Barrel stave osteotomies were performed using 1-2 cm cuts and interval lengths of 4-6 cm (Figure 1). Erythrocyte suspensions were given in accordance with the amount of bleeding from the osteotomy sites in the aspirator bottle and the number of saturated sponges. A mini-vac drain was placed on the epidural site. Calvarial periosteum sites were fixed loosely from various parts. The subcutaneous site was closed with vicryl and the skin was closed with silk sutures.

A whole blood count was obtained at the first and sixth hour postoperatively. Patients with hemoglobin levels below 10 or with hematocrit levels which had decreased more than $5 \%$ between the first and sixth hour were administered a $10 \mathrm{mg} /$ $\mathrm{kg}$ erythrocyte transfusion. The cases were followed in the intensive care unit of neurosurgery department for 24 hours during the initial postoperative period. They were discharged on postoperative day three or four and called to the outpatient clinics on postoperative day seven in order to perform early control. Magnetic resonance imaging (MRI) was performed on all cases six months postoperatively.

\section{- RESULTS}

In the current study, 100 males (69.9\%) and 43 females $(30.1 \%)$ were included. Of the cases 98 (68.5\%) had metopic, $30(20.9 \%)$ had sagittal, $9(6.2 \%)$ had metopic and sagittal, and $6(4 \%)$ had coronal synostosis, $4(2.7 \%)$ being unilateral and $2(1.3 \%)$ being bilateral (Figure 2$)$.

Of the cases, the mean age was 7.4 months (1-48 months), mean body weight was $8.26 \mathrm{~kg}(3.5-16.0 \mathrm{~kg})$ and mean height was $65.5 \mathrm{~cm}(49-97 \mathrm{~cm})$, respectively. Mean anesthesia duration was 148.7 minutes (60-270 minutes) and mean surgical time was 124.4 minutes (40-240 minutes), respectively. The preoperative mean hemoglobin level was $11.6 \mathrm{~g} / \mathrm{dL}(9.0-$ $17.1 \mathrm{~g} / \mathrm{dL}$ ) and mean hematocrit level was $34.4 \%$ (27-54\%), respectively. In the intraoperative period, all the cases were administered a mean $8.61 \mathrm{ml} / \mathrm{kg}$ erythrocyte suspension (ES). In the postoperative period, 92 cases (64.0\%) were administered a mean $7.98 \mathrm{ml} / \mathrm{kg}$ erythrocyte suspension. The postoperative first hour mean hemoglobin level was $11.1 \mathrm{~g} /$ $\mathrm{dL}(8.9-14.7 \mathrm{~g} / \mathrm{dL})$ and the mean hematocrit level was $34.8 \%$ (26.4-48.0\%). The postoperative sixth hour mean hemoglobin level was $10.3 \mathrm{~g} / \mathrm{dL}(8.7-15.1 \mathrm{~g} / \mathrm{dL})$ and the mean hematocrit level was $33.5 \%(25.4-46.1 \%)$ (Table I).

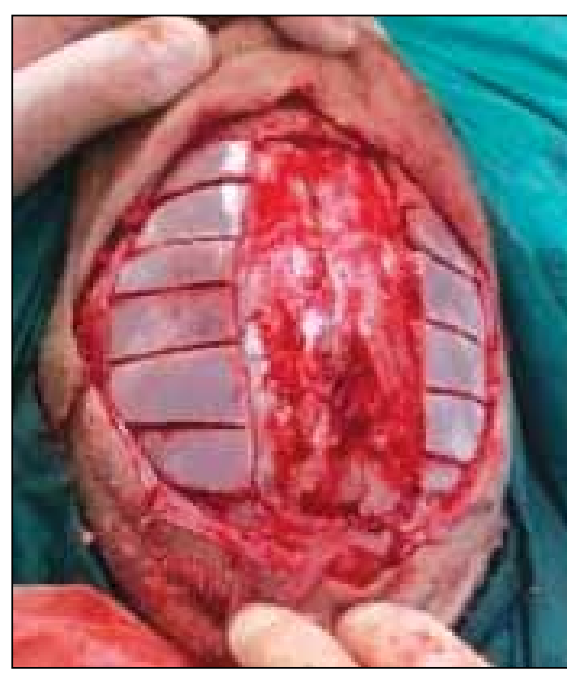

Figure 1: Barrel stave osteotomy in a patient with sagittal synostosis.

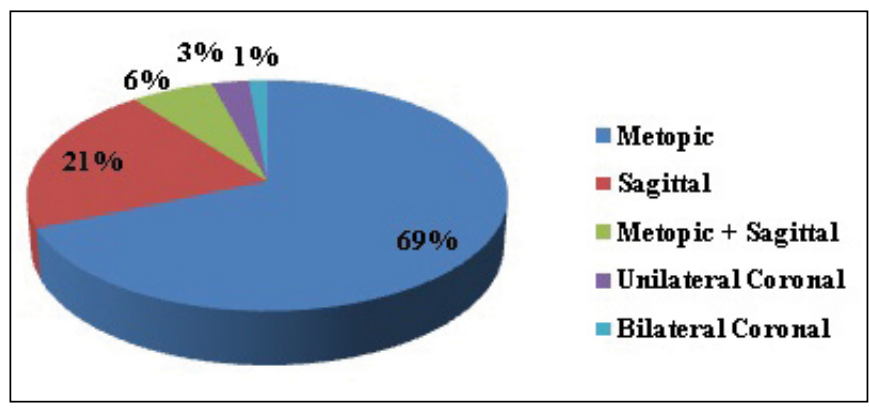

Figure 2: The classification of craniosynostosis of the cases. 
No postoperative pyrexia or allergenic reaction was recorded and there were no mortalities. There were two (1.3\%) surgical site infections, one $(0.7 \%)$ thin epidural hematoma that did not require surgical intervention, one $(0.7 \%)$ methemoglobinemia, one $(0.7 \%)$ cerebrospinal fluid (CSF) leakage that stopped after using OPSITE ${ }^{\circledR}$ spray and one $(0.7 \%)$ re-ossification that required surgical intervention.

\section{- DISCUSSION}

Management of blood loss is an important issue in craniosynostosis surgery both in the intraoperative and postoperative periods (19). A small amount of blood loss may result in hypotension and cardiac arrest in an infant with craniosynostosis (7). Thus, attention should be paid both in the intraoperative and postoperative periods. Different methods have been attempted in order to decrease blood loss and to prevent transfusion complications. Even though there have been many efforts to improve blood sparing during craniosynostosis surgery, including minimally invasive and endoscopic techniques $(6,10,12,14)$, the use of autologous blood obtained from the patient in the preoperative period (11), intraoperative aminocaproic acid (17), tranexamic acid $(4,8)$, preoperative recombinant human erythropoietin (15) and fibrin glue (25) applications, there is no concise or universally accepted procedure yet.

In the current study, of the 143 cases, 100 were male $(69.9 \%)$ and 43 were female (30.1\%). Although in recent studies, generally male-to-female ratios were equal or females had numerical superiority $(1,5,10,19,24)$, the obvious majority of boys in our study may be due to the sociodemographic characteristics of the cases.

Certain factors may influence timing in craniosynostosis surgery. As there is no increase in intracranial pressure, craniosynostosis surgery is performed in the first 3-6 months of life; in patients who will benefit from a barrel stave osteotomy, it is most appropriate to postpone the surgery to 5-6 months

Table I: Characteristics of the Cases

\begin{tabular}{lcc}
\hline & Mean & $\begin{array}{c}\text { Minimum- } \\
\text { Maximum }\end{array}$ \\
\hline Age (months) & 7.4 & $1-48$ \\
\hline Body weight $(\mathrm{kg})$ & 8.26 & $3.5-16$ \\
\hline Height (cm) & 65.5 & $49-97$ \\
\hline Duration of anaesthesia (min) & 148.7 & $60-270$ \\
\hline Mean surgical time (min) & 124.4 & $40-240$ \\
\hline Preoperative Hb (mg/dL) & 11.6 & $9-17.1$ \\
\hline Preoperative Htc (\%) & 34.4 & $27-54$ \\
\hline Intraoperative ES (ml) & 61.2 & $15-200$ \\
\hline Intraoperative ES (ml/kg) & 8.61 & 7.98 \\
Postoperative $1^{\text {st }}$ hour Hb & 11.1 & $8.9-14.7$ \\
\hline Postoperative 6 ${ }^{\text {th }}$ hour Hb & 11.1 & $8.7-15.1$ \\
\hline Postoperative ES (n=92) & 49.7 & $15-160$ \\
\hline
\end{tabular}

ES: Erythrocyte suspension, Hb: Hemoglobin, Htc: Hematocrit. of age. In the study of Dahmani et al. (5), which included 41 patients diagnosed with craniosynostosis, the mean age was 7.2 months; in the study of Steinbok et al. (23), including 32 cases, the mean age was 8.3 months. In the current study, the mean age was 7.4 months, in accordance with the literature.

In our study, the first and most prevalent cases were metopic $(69.2 \%)$, the second were sagittal $(20.2 \%)$ and the third were metopic+sagittal (6.2\%). However, in a number of studies, sagittal synostosis is reported to be more prevalent $(1,3,22)$. In our cases, the high prevalence of metopic synostosis may be due to their demographic characteristics.

During surgical procedures, elongation of surgical time is the most important factor that influences bleeding (26). Thus, the experience of the surgical team may reduce the duration of surgery and also indirectly reduce the bleeding. In our study, the mean surgical time was 124.4 (60-270 minutes) minutes. However, in the literature there are many studies with significantly longer surgical times $(2,13,24,26)$. White et al. (26), reported a mean surgical time of 5.11 hours in their study determining the markers of blood loss in frontoorbital advancement remodeling surgery. Kang et al. (13) reported a mean surgical time of 3.5 hours in their study on the management of blood loss in craniosynostosis surgery. In the current study, our duration of operation was shorter than that in other studies, probably due to the efficiency of our collaborative surgical team.

There is an insensible blood leakage from the cut bone when barrel stave osteotomy is being performed on the calvarium. This is the main difference from the other procedures. In the current study all of the cases were administered ES during barrel stave osteotomy. The mean amount of intraoperative ES was $61.2 \mathrm{ml}(15-200 \mathrm{ml})$. White et al. (26), in their study with 116 cases, administered more than $300 \mathrm{ml}$ ES and used intraoperative fibrin glue in order to decrease postoperative bleeding. Shah et al. (20), in their study comparing endoscopic and open methods, found mean blood amount given intraoperatively as $218 \mathrm{ml}$ in the open method with 89 cases undergoing barrel stave osteotomy. Moon et al. (16), applying barrel stave osteotomy and " $Z$ " osteotomy together in 5 cases with sagittal synostosis, reported the mean blood amount given intraoperatively as $452 \mathrm{ml}$. Zackary et al. (27), applying barrel stave osteotomy to 100 cases with craniosynostosis, reported the mean blood amount given intraoperatively as $302.8 \mathrm{ml}$. Jeong et al. (9), in their study on the complications of 94 cases with craniosynostosis, reported the mean blood amount given intraoperatively as $1231.5 \mathrm{ml}$. In the current literature, compared to other open-types of barrel stave osteotomy applications in craniosynostosis surgery, we administered lower amounts of blood. Both in the above-mentioned studies and also in our current study, there was bleeding in cases undergoing barrel stave osteotomy and blood had to be administered. In surgery, although blood transfusion was performed in each case, the preoperative mean hemoglobin level was measured as 11.6 $\mathrm{g} / \mathrm{dL}$; this decreased to $11.1 \mathrm{~g} / \mathrm{dL}$ in the first postoperative hour and $10.3 \mathrm{~g} / \mathrm{dL}$ in sixth postoperative hour. ES given as $0.5-1.0 \mathrm{ml} / \mathrm{kg}$ is a tolerable amount by the patients and is not expected to exert a serious effect on hemodynamics. In some 
cases, although a $200 \mathrm{cc}$ blood transfusion was performed according to estimated blood loss, our findings of a decrease in postoperative hemoglobin levels supports our view of blood administration in accordance with intraoperatively estimated blood loss.

\section{CONCLUSION}

Barrel stave osteotomy is a widely used procedure in neurosurgery applications for craniosynostosis surgery. According to our results, ES should be administered to patients at the beginning of an osteotomy as there are both intraoperative and postoperative leakage-type bleedings from the bones undergoing the osteotomy, and sometimes these bleedings may reach a clinically significant volume and could possibly prove fatal. The volume of this bleeding is difficult to measure objectively and only may be estimated by the experience of the surgeon and the intraoperative observation of the anesthetist. Some objective criteria that may be applied is the count of used sponges with an approximated volume of blood absorbed and the amount of intraoperative irrigation fluid used which should be closely monitored by an experienced anesthetist who is accustomed to pediatric cases. The bleeding volume is particularly important for an infant in the first year of life, especially within the first six months. The lost blood volume should be replaced immediately.

\section{REFERENCES}

1. Anantheswar YN, Venkataramana NK: Pediatric craniofacial surgery for craniosynostosis: Our experience and current concepts: Part-1. J Pediatr Neurosci 4:86-99, 2009

2. Chan JWH, Stewart CL, Stalder MW, Hilaire H, McBride L, Moses $\mathrm{MH}$ : Endoscope-assisted versus open repair of craniosynostosis: A comparison of perioperative cost and risk. J Craniofac Surg 24: 170-174, 2013

3. Çeltikçi E, Börcek AÖ, Baykaner MK: Craniosynostosis. Türk Nöroşir Derg 23: 132-137, 2013 (in Turkish)

4. Dadure C, Sauter M, Bringuier S, Bigorre M, Raux O, Rochette A, Canaud N, Capdevila X: Intraoperative tranexamic acid reduces blood transfusion in children undergoing craniosynostosis surgery: A randomized double-blind study. Anesthesiology 114: 856-861, 2011

5. Dahmani S, Orliaguet GA, Meyer PG, Blanot S, Renier D, Carli PA: Perioperative blood salvage during surgical correction of craniosynostosis in infants. Br J Anaesth 85: 550-555, 2000

6. Erşahin Y: Endoscope-assisted repair of metopic synostosis. Childs Nerv Syst 29: 2195-2199, 2013

7. Faberowski LW, Black S, Mickle JP: Blood loss and transfusion practice in the perioperative management of craniosynostosis repair. J Neurosurg Anesthesiol 11:167-172, 1999

8. Goobie SM, Meier PM, Pereira LM, McGowan FX, Prescilla RP, Scharp LA, Rogers GF, Proctor MR, Meara JG, Soriano SG, Zurakowski D, Sethna NF: Efficacy of tranexamic acid in pediatric craniosynostosis surgery. Anesthesiology 114:862-871, 2011

9. Jeong JH, Song JY, Kwon GY, Baek SH, Kim JC, Choi TH, Kim $\mathrm{S}$ : The results and complications of cranial bone reconstruction in cases with craniosynostosis. J Craniofac Surg 24:1162-1167, 2013
10. Jimenez DF, Barone CM: Early treatment of coronal synostosis with endoscopy-assisted craniectomy and postoperative cranial orthosis therapy: 16-year experience. J Neurosurg Pediatrics 12 : 207-219, 2013

11. Jimenez DF, Barone CM: Intraoperative autologous blood transfusion in the surgical correction of craniosynostosis. Neurosurgery 37: 1075-1079,1995

12. Kaisorn L, Chaichana KL, Jallo GI, Dorafshar AH, Ahn ES: Novel use of an ultrasonic bone-cutting device for endoscopic-assisted craniosynostosis surgery. Childs Nerv Syst 29:1163-1168, 2013

13. Kang JK, Lee SW, Baik MW, Son BC, Hong YK, Jung CK, Ryu $\mathrm{KH}$ : Perioperative specific management of blood volume loss in craniosynostosis surgery. Childs Nerv Syst 14: 297-301, 1998

14. Massimi L, Di Rocco C: Mini-invasive surgical technique for sagittal craniosynostosis. Childs Nerv Syst 28:1341-1345, 2012

15. Meara JG, Smith EM, Harshbarger RJ, Farlo JN, Matar MM, Levy ML: Blood-conservation techniques in craniofacial surgery. Ann Plastic Surg 24: 525-529, 2005

16. Moon SH, Paik HW, Byeon JH: Treatment of sagittal synostosis: Subtotal cranial vault remodelling with right-angled Z-osteotomies. J Plast Reconstr Aesthet Surg 63: 1787-1793, 2010

17. Oppenheimer AJ, Ranganathan K, Levi B, Strahle JM, Kapurch $\mathrm{J}$, Muraszko KM, Buchman SR: Minimizing transfusions in primary cranial vault remodeling: The role of aminocaproic acid. J Craniofac Surg 25:82-86, 2014

18. Raja RA, Khemani VD, Sheikh S, Khan H: Craniosynostosis: Early recognition prevents fatal complications. J Ayub Med Coll Abbottabad 23:140-143, 2011

19. Seruya M, Oh AK, Rogers GF, Han KD, Boyajian MJ, Myseros JS, Yaun AL, Keating RF: Blood loss estimation during frontoorbital advancement: Implications for blood transfusion practice and hospital length of stay. J Craniofac Surg 23: 1314-1317, 2012

20. Shah MN, Kane AA, Petersen JD, Woo AS, Naidoo SD, Smyth MD: Endoscopically assisted versus open repair of sagittal craniosynostosis: The St. Louis Children's Hospital experience. J Neurosurg Pediatrics 8:165-170, 2011

21. Sharma RK: Craniosynostosis. Indian J Plast Surg 46:18-27, 2013

22. Shin JH, Persing JA: Nonsyndromic craniosynostosis and deformational plagiocephaly. In: Thorne $\mathrm{CH}$ (ed), Grabb and Smith's Plastic Surgery, 6th edn. Philadelphia: Lippincott Williams \& Wilkins, 2007:226-236

23. Steinbok $P$, Heran N, Hicdonmez T, Cochrane DD, Price $A$ : Minimizing blood transfusions in the surgical correction of coronal and metopic craniosynostosis. Childs Nerv Syst 20: 445-452, 2004

24. Wes AM, Paliga JT, Goldstein JA, Whitaker LA, Bartlett SP, Taylor $\mathrm{JA}$ : An evaluation of complications, revisions, and long-term aesthetic outcomes in nonsyndromic metopic craniosynostosis. Plast Reconstr Surg 133:1453-1464, 2014

25. White N, Carver ED, Rodrigues D, Dover S, Magdum S, Nishikawa $\mathrm{H}$, Solanki G: Calvarial remodelling for sagittal synostosis: Does fibrin glue (Tisseel ${ }^{\mathrm{TM}}$ ) reduce post-operative blood transfusion requirements? Childs Nerv Syst 25:867-869, 2009

26. White N, Marcus R, Dover S, Solanki G, Nishikawa H, Millar C, Carver ED: Predictors of blood loss in fronto-orbital advancement and remodeling. J Craniofac Surg 20:378-381, 2009

27. Zakhary GM, Montes DM, Woerner JE, Notarianni C, Ghali GE: Surgical correction of craniosynostosis. A review of 100 cases. J Craniomaxillofac Surg 42:1684-1691, 2014 